\title{
HACIA UNA POLITICA INTEGRAL DE JUVENTUD
}

\author{
JIMENA JORQUERA*
}

SI BIEN ES CIERTO, el tema juvenil ha estado presente en el discurso oficial desde comienzos de la década, no es menos apropiado indicar que el tratamiento que ha tenido desde el accionar de las políticas públicas ha sido deficiente en variados aspectos. Aunque el objeto aquí no sea dar cuenta de manera acabada de los aspectos deficitarios de dichas políticas, que ya casi al terminar el decenio, es fácil percibir que existen graves falencias en el ámbito de la construcción del sujeto joven, insuficiencias en la coordinación programática, déficit en el seguimiento y evaluación de dichas acciones y un marcado desconocimiento de las formas en que los y las jóvenes construyen su experiencia cotidiana. Por otra parte, aunque existen elementos que desde el nivel central permitieron vislumbrar la necesidad de una política integral de juventud, no es posible desconocer que las tensiones administrativas terminaron por colapsar un sistema de articulación nacional que - hoy por hoy- comienza a rearticularse bajo otras directrices, en que lo local, regido por tendencias que valoran la descentralización, poniendo más énfasis en elementos de democratización social, comienza a cobrar importancia, poniendo de relieve el protagonismo de otros actores institucionales, entre ellos las unidades municipales

* $\quad$ Asistente Social, Directora del Departamento de Jóvenes de la Ilustre Municipalidad de Concepción. 
de juventud, en cuanto instancias articuladoras entre el mundo civil y el gobierno local. De igual forma, esa tendencia se ve plasmada en el accionar de los municipios, desde la generación de Planes de Desarrollo Comunal, en donde cada vez con mayor claridad surge el tema de la necesidad de diseñar y construir políticas sociales.

Cercana a esta línea de reflexión, el Departamento de Jóvenes de la Dirección de Desarrollo Comunitario de la Municipalidad de Concepción, viene desarrollando de manera seria, a partir de 1997, un conjunto de acciones tendientes a crear una política comunal de juventud, a partir de la construcción de realidad de los y las jóvenes de la comuna. En un sentido más estricto, de lo que se trata es de generar una política local desde la juventud, razón por la cual, las primeras aproximaciones tuvieron un carácter de investigación-acción.

En esta oportunidad - y en el marco del aniversario de la ciudad - la apuesta es generar un espacio de reflexión ampliado, con expositores de alto nivel en el ámbito local, nacional e internacional, de manera de generar un aporte contundente, que contribuya a la elaboración de políticas locales de juventud.

Con este objetivo, se ha programado de manera conjunta, entre el Departamento de Jóvenes de este municipio y el Centro de Investigación y Difusión Poblacional de Achupallas Viña del Mar (CIDPA), la realización del Seminario «Políticas locales de juventud», el cual contempla además de las metas de reflexión, análisis y generación de propuestas, la publicación de dicha experiencia en la Revista Última Década elaborada por CIDPA, constituyéndose de esta forma en un aporte de mayor cobertura a nivel nacional.

Bienvenidos todas y todos a este Seminario. Muchas gracias.

CONCEPCIÓN, OCTUBRE DE 1999 